\title{
Design and Build Distance Learning Media Based on the Business Simulator-Integrated (SIMBIZ-Integrated) Application to Support the Learning Process of Students Affected by the COVID-19 Pandemic
}

\section{Suryo Hadi Wira Prabowo ${ }^{1}$, Achmad Murdiono1, and Jefry Aulia Martha1, and Nangkula Utaberta ${ }^{2}$}

${ }^{1}$ Department of Management, Faculty of Economic, Universitas Negeri Malang

${ }^{2}$ Halal Product Research Institute, Universiti Putra Malaysia

ORCID:

Suryo Hadi Wira Prabowo: http://orcid.org/0000-0002-6433-841X

\section{Abstract}

The COVID-19 pandemic has a very broad impact. This pandemic not only affects

Corresponding Author:

Achmad Murdiono

achmad.murdiono.fe@um.ac.id

Published: 14 July 2021

Publishing services provided by

Knowledge E

(c) Suryo Hadi Wira Prabowo

et al. This article is distributed

under the terms of the

Commons Attribution License,

which permits unrestricted use and redistribution provided that the original author and source are credited.

Selection and Peer-review under the responsibility of the IRCEB Conference Committee. health, but also education. This is because measures to prevent the spread of the virus require the application of physical distancing. With the application of physical distancing, conventional learning in the classroom cannot be implemented, so distance learning media is needed to continue the teaching and learning process. Learning media in an educational context is a very strategic instrument that helps determine the success of the teaching and learning process. This is because with their limitations, humans are often less able to capture and respond to things that are abstract or that have never been recorded in their memory. Media can support learning by providing a deeper understanding of the material being discussed. This study aimed to design, build and test a business simulator application integration system (SIMBIZ-Integrated) as a distance-learning medium that could help the learning process which has been disrupted due to the COVID-19 outbreak. In addition, this research examines the current conditions of media utilization in distance learning and the effectiveness of the use of business application media in introductory business courses.

Keywords: Distance Learning Media Integration System, Integrated Business Simulator Application (SIMBIZ-Integrated), Prevention of the Impact of the COVID-19 Pandemic

\section{Introduction}

The COVID-19 pandemic has a very broad impact. This pandemic affects not only the health aspect, but also the education aspect (Ting et al., 2020). With the application of physical distancing, conventional learning in the classroom cannot be implemented, 
process (Chatterjee et al., 2020). Therefore, the key word is that teaching staff must be able to compile distance learning media that do not reduce the quality of learning.

The condition of distance learning using online media is not new for the UM campus. However, the challenge in distance learning for business management students is an emphasis on a limited understanding of business on business theories and a lack of practice (Cross et al., 2019). A learning process like this only emphasizes students to master an understanding of business theories. In the end, students can get trapped in the understanding that what they understand is the right thing and can be done in the real world. Therefore, a learning media is needed that brings business facts in the field closer to business cases in classroom learning (Prestridge et al., 2019).

Learning media can support the success of learning because it has various advantages in learning. (Kirkwood and Price, 2014) explains the advantages of learning media, including providing a deeper understanding of the learning material being discussed, explaining abstract learning material to be concrete, presenting learning material to be easier and faster, so that students can easily understand, attract and evoke. attention, interest, motivation, learning activities and creativity of students.

In learning, various types of media can be used, namely visual, auditory, and direct physical activities (Danielsson and Wiberg, 2006). An effective media that students are interested in is games. Likewise, in learning for managerial economics courses. Learning can be assisted using a business simulator application media developed by Heri Pratikto and the research team in 2018, namely SIMBIZ - Business Simulator Application (Pratikto et. Al, 2018). By applying game-based managerial economic learning with a business simulator application, students can experience first-hand the conditions of a business steps.

After implementing the SIMBIZ application which was created in 2018 by Heri Pratikto and the team, it was found that there was an increase in achievement in the form of an increase in the value of understanding from students who have used the SIMBIZ application (Pratikto et. Al., 2018). However, in practice, specifically for monitoring and evaluation, classroom instructors, namely lecturers, have obstacles in carrying out monitoring and evaluation activities in these applications. This is because the SIMBIZ application is still a stand-alone application.

SIMBIZ is said to be a stand-alone application because SIMBIZ is installed on the smartphone of each student as a student. But each application that is installed is not connected between students and the instructor. So that the lecturer uses individual reports from each student which are then submitted to the lecturer in the class. This 
becomes an obstacle by the lecturer as instructor in conducting direct supervision and evaluation of students (Nagro et al., 2019).

Based on the constraints described above, the solution that can solve these problems is to create a dashboard for instructors with an integrated system between students and instructors. Therefore, this study aims to design, build and test a business simulator application integration system (SIMBIZ-Integrated) which functions as a distance learning medium to support the learning process of students affected by the COVID-19 pandemic.

\section{Research Method}

\subsection{Research Approach}

In accordance with the research objectives, this study uses a development approach (Research and Development). Borg and Gall contains a systematic guide to the steps taken by researchers so that the products they design have a standard of feasibility (Cavendish et al., 2020). In this study, the product in question is an application system integration based on the Business Simulator application (SIMBIZ-Integrated) between applications for students and instructors. The following are the stages of research that will be applied to this research.

\subsection{Data Sources}

The type of data in this development uses qualitative descriptive data. Qualitative data is generated from the responses of media experts, material experts and user responses, namely lecturers and students about the products produced. Large-scale trials involving selected students and lecturers will be able to represent and produce outputs that can be used in this research. Overall, this study took a sample of 300 consisting of various state universities in East Java.

\subsection{Data Analysis}

Research on the design and development of a business simulator application integration system is carried out in several stages of analysis, 


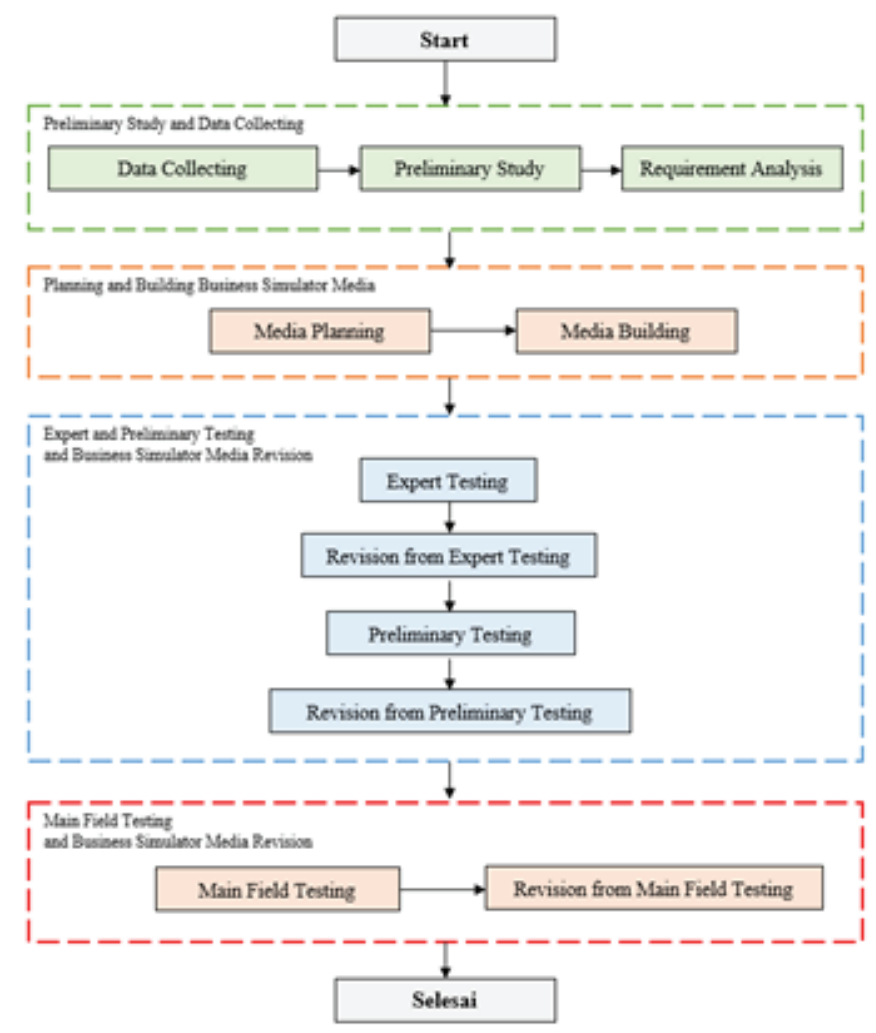

Figure 1: Research and Development Approach Method

\subsubsection{Analysis of Preliminary Studies and Data Collection Stages}

At this stage what is done is gathering information and preliminary studies from previous research or related disciplines. Then perform an analysis of what needs will be included in the media integration system that will be created.

\subsubsection{Analysis of Planning and Compilating of Business Simulator Media Integration System Stages}

At this stage, what is done is starting from planning a business simulator application integration system framework then carrying out the preparation of an application-based business simulator media integration system as the initial form of the product.

\subsubsection{Analysis of Expert \& Limited Scale Trail and Improvement of Busi- ness Simulator Media Integration System Stages}

At this stage what is done is starting from the first trial by experts to validate the material, media, and applications. Then made improvements from the input provided 
by the expert. After that, it was continued with trials on a limited scale which then made improvements from the limited scale trial.

\section{Result and Discussion}

The following are some of the results obtained from the research conducted. The results will be described based on the stages of analysis that have been determined in the research method.

\subsection{Analysis of Preliminary Studies and Data Collection Stages}

In the preliminary study stage and data collection, 2 activities were carried out, namely a preliminary study of distance learning media and data collection used in designing the Integrated Business Simulator (SIMBIZ-Integrated) application. The results of the preliminary study found that games are the most effective learning media. This is because the game will spur someone to continue to try and learn all the obstacles faced, as well as hone the ability to make decisions based on theoretical knowledge gained in lessons in the classroom. In addition, a game in the form of an application on a smartphone is easier for students to use because a smartphone is one of the things that users always carry. So that by utilizing games on smartphones it can be an effective learning media used in lecture learning.

\subsection{Analysis of Planning and Compilating of Business Simulator Media Integration System Stages}

The data that has been collected in the previous stage will be used at this stage in the planning and preparation of the Integrated Business Simulator (SIMBIZ-Integrated) application. The SIMBIZ-Integrated application is designed to have several features that support the distance learning process. Here are some design features of the SIMBIZ Integrated application

\section{- Student Account Login Feature}

This feature contains a login page for student accounts that will use the SIMBIZIntegrated application. On this page students need to enter their NIM (Student Identification Number) and full name which will be the database in this application. After 


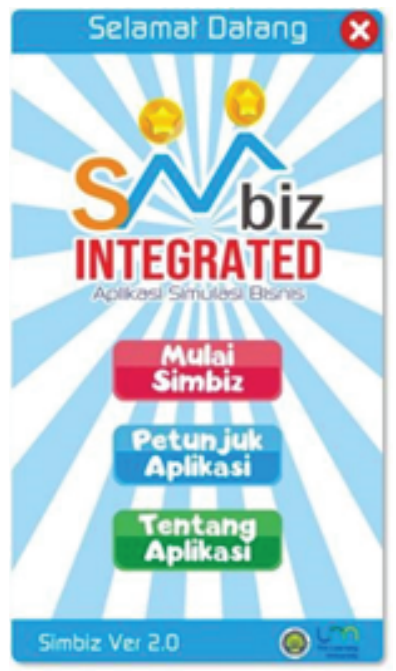

Figure 2: Homepage of Business Simulator Integrated (SIMBIZ-Integrated)
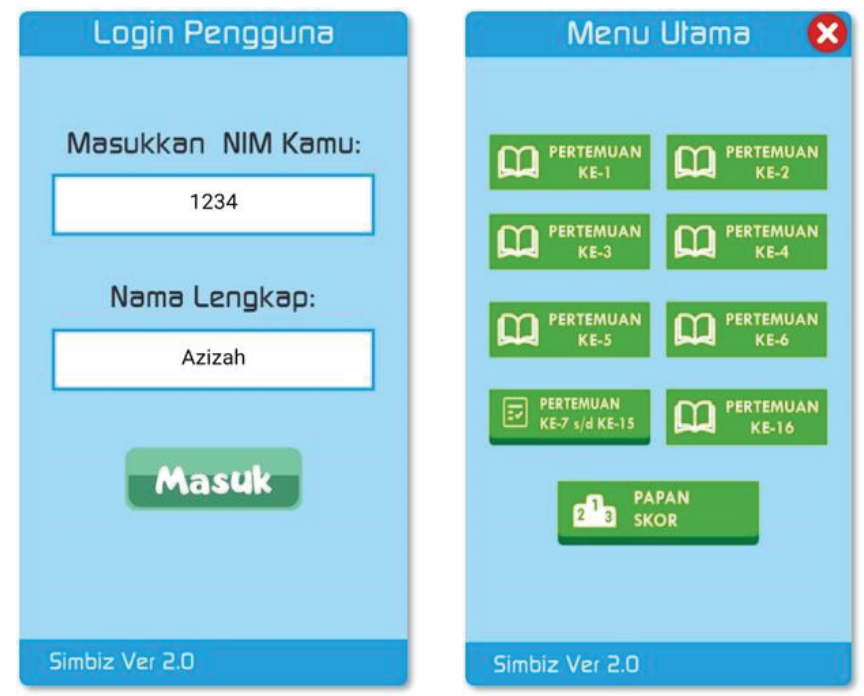

Figure 3: (a) Login Page and (b) Main Menu for Student Account in SIMBIZ-Integrated

students enter their NIM and full name correctly, they will be directed to the main menu page which contains materials and cases in the SIMBIZ-Integrated application.

\section{- Lecturer Account Login Feature}

This feature contains a login page for a lecturer or class administration account that will use the SIMBIZ-Integrated application. On this page, Lecturers need to enter a special code for the Lecturer they have and the full name that has been determined in this application. After the Lecturer enters the special code and full name correctly, the Lecturer will be directed to the main menu page which lists student names, student performance charts, lecturer comments, and the leader board in the SIMBIZ-Integrated application. 


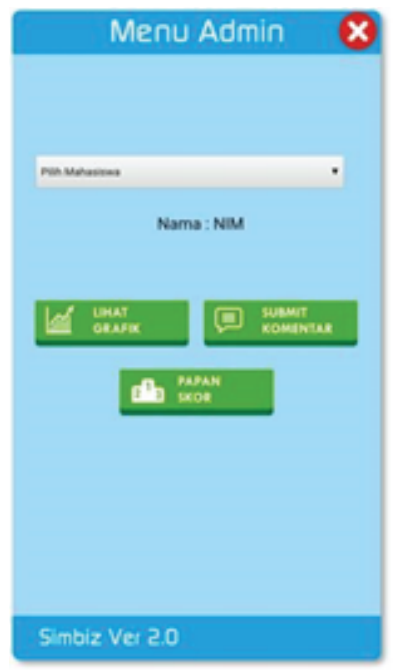

Figure 4: Main Menu for Lecturer Account in SIMBIZ-Integrated

- Explanation of Lecture Materials Feature
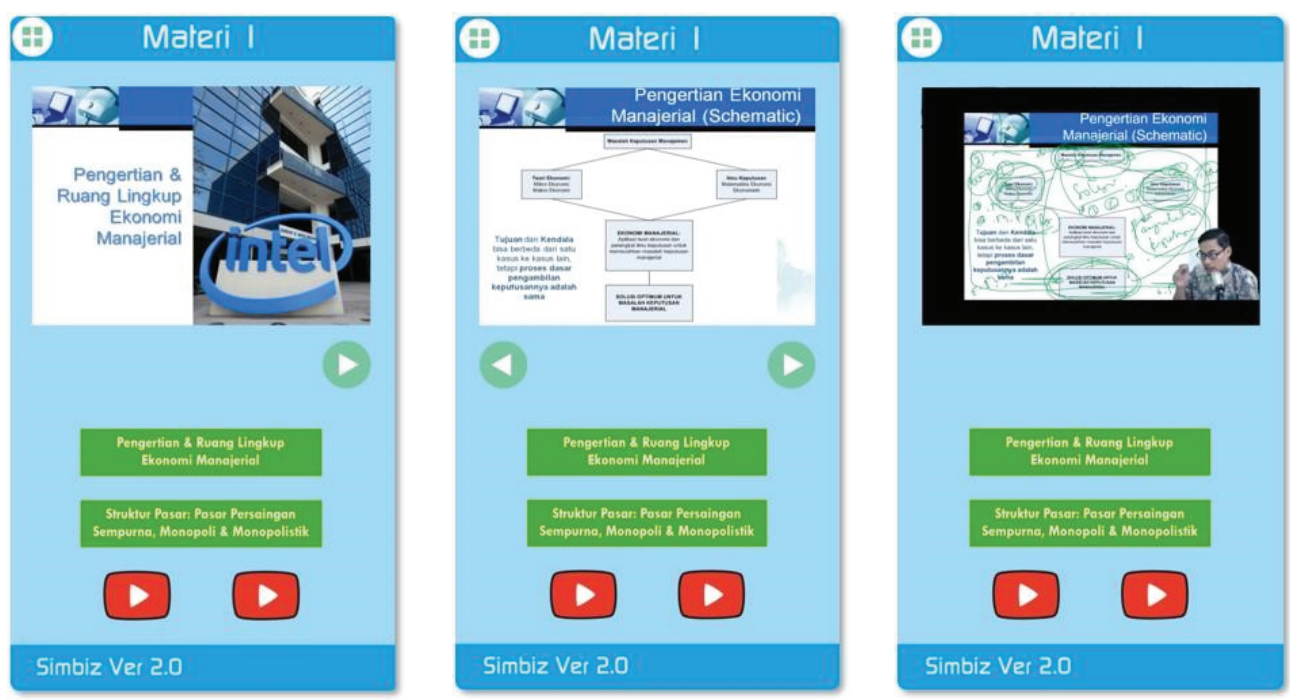

Figure 5: (a) (b) Explanation of Lecture Material and (c) Explanation using video in SIMBIZ-Integrated

This feature contains an explanation of the material that will be found on the student page. Explanation of the material is given in accordance with the sequence of course meetings using the SIMBIZ-Integrated application. The explanation of the material will be explained using 2 media, namely presentation slides and video presentations. Presentation slides can be used for self-study systems, while video presentations can be used for guided learning systems. So that with these 2 media, students can make use of it according to their individual needs.

\section{- Leaderboard Features}




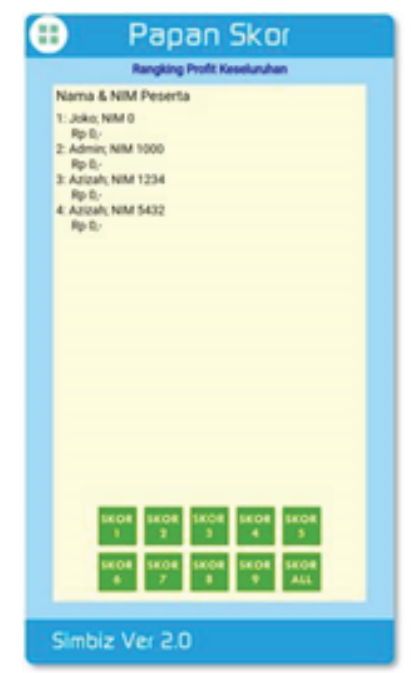

Figure 6: Leaderboard Features in SIMBIZ-Integrated

This feature contains a leader board page. The leader board page is a page designed to show the performance rating of students working on cases according to the lecture meeting stage. A leader board will be created in each case and the entire performance is up to the end of the case. This page is expected to provide an overview of the position of a student's performance in his class.

- Lecturer Comment Feature

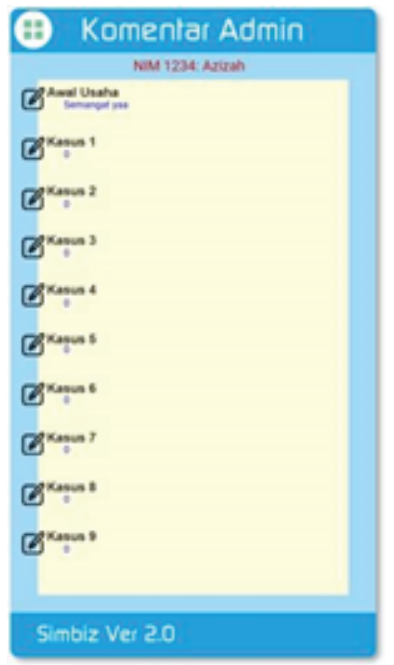

Figure 7: Lecturer Comment Features in SIMBIZ-Integrated

This feature contains a page for commenting by lecturers. This page is designed for lecturers to provide feedback and suggestions for improving student performance. This feature makes this application able to communicate in two directions between students and lecturers. With this feature, it is hoped that 2-way communication will 
occur between lecturers and students to enrich the distance learning system created in the SIMBIZ-Integrated application.

\subsection{Analysis of Expert \& Limited Scale Trail and Improvement of Business Simulator Media Integration System Stages}

There are several analysis which we done for data that we have collected from previous

- Questionnaire Validity and Reliability Test

The reliability test used is Alpha Cronbach. Reliability test results show that the variables in the questionnaire have a Cronbach Alpha coefficient greater than 0.6 so that it can be said that the question instruments used in users and expert questionnaires for Business Simulator Integrated (SIMBIZ-Integrated) are reliable.

- Result of Expert Judgement

The assessment of Business Simulator Integrated (SIMBIZ-Integrated) application is carried out by experts or practitioners through assessment instruments based on existing theories and then used as indicators in expert judgment.

TABLE 1: Result of Expert Judgement Score

\begin{tabular}{|l|c|c|}
\hline Variable & Expert Score & Conclusion \\
\hline Programming & $85,6 \%$ & Proper \\
\hline Content & $87,3 \%$ & Proper \\
\hline
\end{tabular}

Based on table 1, it can be seen that the acceptance score is above $80 \%$, so it is stated that based on two elements of assessment, aspects of programming and content. The Business Simulator Integrated (SIMBIZ-Integrated) application that is made is considered good as a distance learning media and business simulator. Thus, the experts in this study agreed to accept the application Business Simulator Integrated (SIMBIZ-Integrated) which had been made to function as a distance learning media.

- Result of User Acceptance

An assessment of the level of acceptance of The Business Simulator Integrated (SIMBIZ-Integrated) application by the lecturer and students was conducted to find out whether the lecturer and students was satisfied and helped in distance learning with the help of the Business Simulator Integrated (SIMBIZ-Integrated) application as a learning media. The results of the lecturers' and student's assessment of the Business 
Simulator Integrated (SIMBIZ-Integrated) application as a distance learning media are explained in the following table.

TABLE 2: Result of User Acceptance Score

\begin{tabular}{|l|c|c|}
\hline Variable & Expert Score & Conclusion \\
\hline Display & $84,3 \%$ & Accepted \\
\hline Content & $87,3 \%$ & Accepted \\
\hline Benefit & $85,1 \%$ & Accepted \\
\hline
\end{tabular}

The table above shows that the acceptance score of thinkgather.com application as a networking platform is more than $80 \%$ which means that based on the appearance, material aspects, and also the benefits of the Business Simulator Integrated (SIMBIZIntegrated) application that is made is very well assessed by lecturers and students can attract their interest in using the SIMBIZ-Integrated application.

\section{Conclusion and Suggestion}

\subsection{Conclusion}

The conclusion of this research is that the Integrated Business Simulator (SIMBIZ Integrated) application can increase the desire to learn and the results obtained by students at the end of using the application. This is indicated by the high score of measurements made on the users of this application which is equal to $84,3 \%$ (Display), $87,3 \%$ (Content), and $85,1 \%$ (Benefit). Those parameters are above $80 \%$ in all parameters. This shows that the Integrated Business Simulator (SIMBIZ Integrated) application has been designed and built properly to achieve the goals of making the application based on existing problems.

\subsection{Suggestion}

There are several suggestions that can be given in this research. From the application side, further application development is expected to be used separately between classes in the lecture. From the research side, further research can also measure the level of user acceptance of new technology. Not only direct users, but also secondary users such as parents, fellow lecturers, and campus administrators. 


\section{References}

[1] Cavendish, W., et al. (2020). Teacher Perceptions of Implementation Practices to Support Secondary Students in Special Education. Preventing School Failure: Alternative Education for Children and Youth, issue 64, pp. 19-27.

[2] Chatterjee, A., Ghosh, K. and Chatterjee, B. (2020). A Study on Content Selection and Cost-Effectiveness of Cognitive E-Learning in Distance Education of Rural Areas. In J. K. Mandal and D. Bhattacharya (Eds.), Emerging Technology in Modelling and Graphics. Singapore: Springer, pp. 783-786.

[3] Cross, S., et al. (2019). Distance Learners' Use of Handheld Technologies. The International Review of Research in Open and Distributed Learning, issue 20,pp.1-19. https://doi.org/10.19173/irrodl.v20i2.4040.

[4] Danielsson, K. and Wiberg, C. (2006). Participatory Design of Learning Media: Designing Educational Computer Games with and for Teenagers.Interactive Technology and Smart Education., issue 3, pp. 275-291.

[5] Kirkwood, A. and Price, L. (2014). Technology-Enhanced Learning and Teaching in Higher Education: What is 'Enhanced' and How Do We Know? A Critical Literature Reviews. Learning, media and technology, 39(1), pp. 6-36.

[6] Nagro, S. A., Fraser, D. W. and Hooks, S. D. (2019). Lesson Planning with Engagement in Mind: Proactive Classroom Management Strategies for Curriculum Instruction. Intervention in School and Clinic, 54(3), pp. 131-140.

[7] Pratikto, H., Prabowo, S. W., Murdiono, A., \& Basuki, A. (2019). The Role of Business Simulator Games Implementation in Improving the Ability of Analysis and Business Decision Making Independently for Students (Literature Research). KnE Social Sciences, 1005-1010.

[8] Prestridge, S., Tondeur, J. and Ottenbreit-Leftwich, A. T. (2019). Insights from ICT-Expert Teachers About the Design of Educational Practice: The Learning Opportunities of Social Media. Technology, Pedagogy and Education, 28(2), 157172.

[9] Ting, D. S. W., et al. (2020). Digital Technology and COVID-19. Nature medicine, 26(4), pp. 459-461. 